SUPPORTING INFORMATION

\title{
Corrosion Properties of Polydopamine Coatings formed in One-step Immersion Process on Magnesium
}

Ferdinand Singer*, Magdalena Schlesak*, Caroline Mebert*, Sarah Höhn*, Sannakaisa Virtanen ${ }^{*, * *}$

* Chair for Surface Science and Corrosion, Department for Materials Science, University of ErlangenNuremberg, Martensstr. 7, 91058 Erlangen, Germany

** Corresponding author: virtanen@ww.uni-erlangen.de 
Supporting information 1 :

Table S1) wt $\%$ of elements obtained by XPS on Mg immersed in TBS and TBS + PD for $2 \mathrm{~h}$

\begin{tabular}{l|llll} 
& Mg2 $p$ & O1s & C1s & N1s \\
\hline TBS & 33.5 & 55.5 & 10 & 1 \\
TBS + PD & 17.9 & 34.7 & 42.8 & 4.6
\end{tabular}


Supporting information 2:

Table S2) FTIR peak assignment for a) Mg immersed in TBS only, b) PD derived without the presence of Mg, c) FTO coated with PD. d) Mg coated with Polydopamine

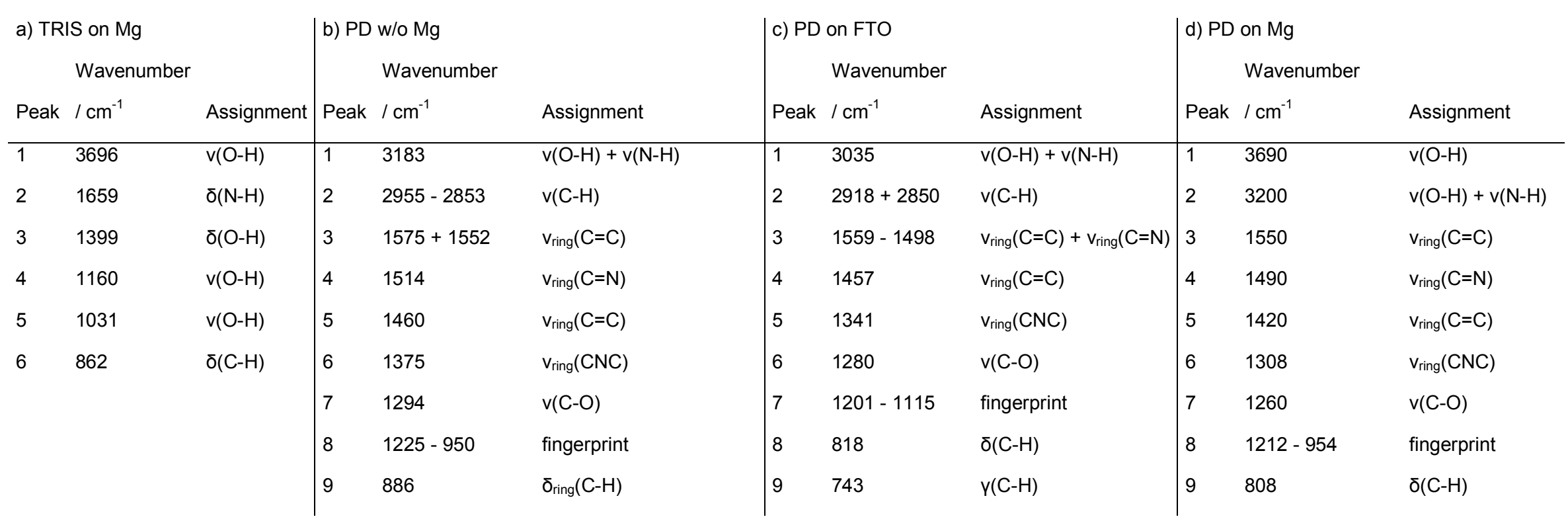




\section{Supporting information 3:}

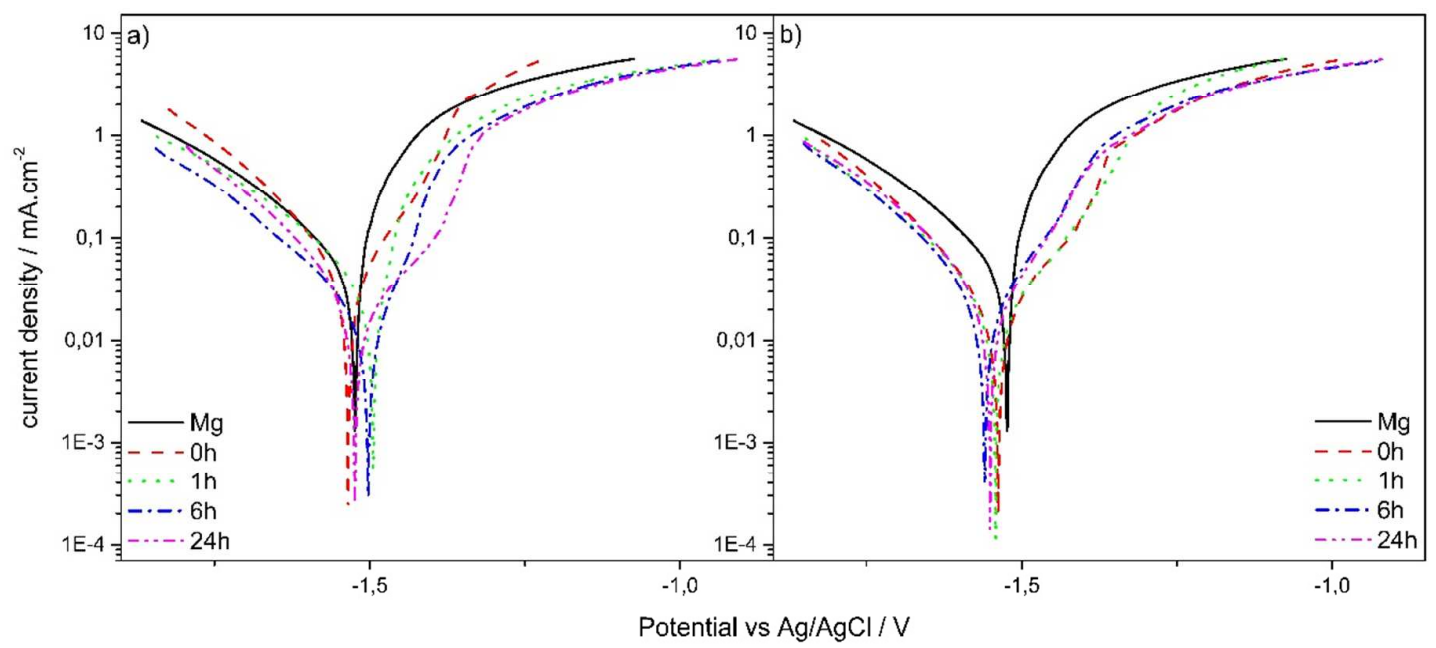

Figure S1) Corrosion behavior measured in $0.1 \mathrm{M} \mathrm{NaCl}$ solution in dependency of prepassivation time in $1 \mathrm{M}$ $\mathrm{NaOH}_{\mathrm{aq}}$ of bare $\mathrm{Mg}, \mathrm{Mg}$ either immersed in TBS with pH 10 (a) or Mg coated with PD in TBS with pH $10+2$ $\mathrm{mg} / \mathrm{ml}$ dopamine for $2 \mathrm{~h}$

Supporting information 4:

Table S3) $\mathrm{E}_{\text {corr }}$ and $\mathrm{i}_{\text {corr }}$ in $0.1 \mathrm{M} \mathrm{NaCl}$ of bare $\mathrm{Mg}$, Mg immersed in TBS with $\mathrm{pH} 10$ and $\mathrm{Mg}$ coated in TBS with $\mathrm{pH}$ 10 with $2 \mathrm{mg} / \mathrm{ml}$ dopamine for $2 \mathrm{~h}$ in dependency of prepassivation time in $1 \mathrm{M} \mathrm{NaOH}$

\begin{tabular}{c|cccc|cccc} 
& \multicolumn{1}{|l|}{$\begin{array}{l}\text { TBS } \\
\mathrm{E}_{\text {corr }} / \mathrm{V}\end{array}$} & \pm & $\mathrm{i}_{\text {corr }} / \mu \mathrm{A} / \mathrm{cm}^{2}$ & \pm & $\begin{array}{l}\mathrm{PD} \\
\mathrm{E}_{\text {corr }} / \mathrm{V}\end{array}$ & \pm & $\mathrm{i}_{\text {corr }} / \mu \mathrm{A} / \mathrm{cm}^{2}$ & \pm \\
\hline bare Mg & -1.53 & 0.02 & 50.2 & 15.9 & & & & \\
w/o prepassivation & -1.54 & 0.01 & 33.8 & 3.3 & -1.50 & 0.05 & 10.9 & 5.6 \\
1h & -1.50 & 0.02 & 31.7 & 16.4 & -1.54 & 0.01 & 20.6 & 6.4 \\
6h & -1.51 & 0.02 & 13.3 & 2.6 & -1.56 & 0.01 & 22.5 & 2.9 \\
$24 \mathrm{~h}$ & -1.52 & 0.01 & 12.4 & 2.1 & -1.55 & 0.02 & 20.6 & 3.6
\end{tabular}

